\title{
Effect of food density on male appearance and ephippia production in a tropical cladoceran, Moina micrura Kurz, 1874
}

\begin{abstract}
A study was conducted to investigate the effects of different food concentrations consisting of Nannochloropsis oculata $(4 \times 102,4 \times 104,4 \times 106$ cells mlī 1 and control) on male and ephippia production in a tropical cladoceran, Moina micrura. The highest number of males (186.7 \pm 13.4 males $1 \overline{1} 1$ 1) was produced in cultures fed with $4 \times 102$ cells mlī 1 of N. oculata (FC 3) when the population density reached > 1600 individuals $1 \overline{1} 1$. Similarly, the highest total mean number of ephippia (160.0 \pm 0.0 ephippia $1 \bar{l} 1)$ was achieved in M. micrura culture supplied with $4 \times 102$ cells mlī 1 of N. oculata (FC 3). The second highest ephippia density was found in M. micrura cultures fed with $4 \times 104$ cells mlī 1 of N. oculata (FC 2) which produced a mean total of $93.3 \pm 13.4$ ephippia $1 \bar{l} 1$ in a population density of $>3000$ individuals $1 \overline{1} 1$. However, with a population density of $>4000$ individuals $l \overline{1} 1$, but fed with the highest food concentration of $4 \times 106$ cells mlī $1 \mathrm{~N}$. oculata (FC 1), no ephippia was produced although males were present in the culture. This study illustrates that ephippia were produced in high density cultures with the presence of males and insufficient food supply. Crowding could trigger the production of males, but was not an adequate stress factor for inducing the formation of ephippia. Similarly, food limitation alone did not induce the production of males and ephippia without crowding.
\end{abstract}

Keyword: Cladoceran males; Ephippia; Resting eggs; Moina micrura; Parthenogenetic reproduction; Tropical zooplankton 